\title{
Caracterização fitossociológica da vegetação no entorno de nascentes de um fragmento de Floresta Ombrofila Mista Montana na bacia do rio das Pedras, Guarapuava (PR)
}

\author{
Phytosociological characterization of the vegetation around water springs \\ of the fragment of mixed ombrophilous forest in watershed of rio das \\ Pedras, Guarapuava (PR)
}

\author{
Thais Espinola de Oliveira Lima ${ }^{1(*)}$ \\ Roberto Tuyoshi Hosokawa ${ }^{2}$ \\ Sebastião do Amaral Machado ${ }^{3}$ \\ Umberto Klock ${ }^{4}$
}

\section{Resumo}

Foi inventariado um fragmento de Floresta Ombrófila Mista Montana, pouco antropizado, com duas nascentes distanciadas 1,5 metros uma da outra, integrantes da bacia hidrográfica do rio das Pedras, na zona rural do município de Guarapuava, Paraná-Brasil (25'19'30”S e 51²3'55”W), com o objetivo de contribuir para um maior conhecimento da composição florística e fitossociológica da região bem como estudar a importância da vegetação na preservação da qualidade da água que aflora dessas nascentes. Às margens das nascentes foram instaladas 14 parcelas de $200 \mathrm{~m}^{2}$, onde foram inventariados 484 indivíduos, com DAP (diâmetro a altura do peito) mínimo de $5 \mathrm{~cm}$, distribuídos em 23 famílias com 32 espécies. O valor do índice de diversidade de Shannon foi de 2,406. As famílias Fabaceae, Lauraceae, Sapindaceae e Solanaceae foram as que apresentaram maior riqueza de espécies (3). Entre essas três famílias, chama a atenção a Sapindaceae que responde por $43 \%$ do total de indivíduos amostrados. A densidade total estimada foi de 1.728 indivíduos/ ha, com DAP médio de 10,32 cm e área basal de 29,82 $\mathrm{m}^{2} / \mathrm{h}$. De acordo com a variável valor de importância (VI), as seis espécies que mais se destacaram foram:

I Dra.; Bióloga; Professora do Centro Universitário Curitiba; Endereço: Rua Chile, 1678, CEP: 80220-18I, Curitiba, Paraná, Brasil; E-mail: toliveiralima@gmail.com $\left(^{*}\right)$ Autora para correspondência.

2 Ph.D.; Engenheiro Florestal; Professor do Departamento de Ciências Florestais da Universidade Federal do Paraná, UFPR; Bolsista de Produtividade em Pesquisa do CNPq; Endereço:Av. Lothário Meissner, 3400, CEP: 80210-I70, Curitiba, Paraná, Brasil; E-mail: rth@japan.org.br

3 Dr.; Engenheiro Florestal; Professor Sênior do Departamento de Ciências Florestais da Universidade Federal do Paraná; Bolsista de Produtividade em Pesquisa do CNPq; Endereço:Av. Lothário Meissner, 3400, CEP: 80210-170, Curitiba, Paraná, Brasil; Email: samachado@ufpr.br E-mail: samachado@ufpr.br

4 Dr.; Engenheiro Florestal; Professor Associado do Departamento de Engenharia de Tecnologia Florestal da Universidade Federal do Paraná, UFPR; Bolsista de Produtividade em Pesquisa do CNPq; Endereço: Av. Lothário Meissner, 3400, CEP: 80210-170, Curitiba, Paraná, Brasil; E-mail: klockuer@ufpr.br

\begin{tabular}{llllll}
\hline Ambiência Guarapuava (PR) & v.8 n.2 & p. 229 - 244 & Maio/Ago. 2012 & ISSN 1808 - 025 I
\end{tabular}


Matayba elaeagnoides Radlk; Ocotea puberula (Rich.Nees; Mimosa scabrella Benth; Myrsine coriaceae (Sw.) R. Br. ex Roem. \& Shult; Erythrina falcata Benth; Solanum. pseudoquina A.St.-Hil.. Elas respondem, aproximadamente, por $18,75 \%$ do total de espécies, $70,25 \%$ do total da densidade e por $85,55 \%$ do total da dominância. As análises biológicas (coliformes totais e termotolerantes) e físico-químicas ( $\mathrm{pH}$, turbidez, cor e fluoretos) da água das nascentes mostram que a vegetação, mesmo em processo de regeneração está desempenhando de forma eficiente seu papel, já que os resultados dos exames laboratoriais, tomando-se como padrão aqueles prescritos na legislação (Portaria no 518/2004 do Ministério da Saúde e Resolução $n^{\circ}$ 357/2005 do CONAMA) não detectaram contaminação.

Palavras-chave: Floresta Ombrófila Mista Montana; nascentes; análise físicoquímica e biológica de água; composição florística e fitossociologica.

\section{Abstract}

This study was carried out in a fragment of Montane Mixed Ombrophylus Forest, little disturbed, with two springs 1.5 meters apart from each other, members of the rio das Pedras watershed in the Municipality of Guarapuava, Paraná State, Brazil

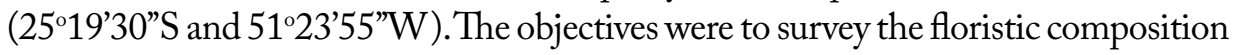
and phytosociologic parameters of the region, as well as, to study the importance of vegetation in maintaining the quality of water these headwaters. On the banks of the headwaters were installed 14 plots of $200 \mathrm{~m}^{2}$, where 484 individuals were surveyed, with minimal diameter at breast height $(\mathrm{DBH})$ of $5 \mathrm{~cm}$, distributed in 23 families with 32 species. The total density was 1728.57 individuals per hectare with medium DBH of $10.32 \mathrm{~cm}$ and basal area of $29.82 \mathrm{~m}^{2} / \mathrm{ha}$. The Shannon diversity index was of 2,406. The families Fabaceae, Lauraceae, Sapindaceae and Solanaceae were the ones that presented the biggest richness of species (3). Among these three families Sapindaceae calls attencion that it shows $43 \%$ of those individuals sampled. According to the variable importance value (VI) the six species that stood out were: Matayba elaeagnoides Radlk; Ocotea puberula (Rich.); Mimosa scabrella Benth.; Myrsine coriacea (Sw.) R.Br.ex Roem.\&Schult; Erythrina falcata Benth.; Solanum.pseudoquina A.St.-Hil. They respond to approximately $18.75 \%$ of the total species, $70.25 \%$ of the total density and $85.55 \%$ of total dominance. The biological (total and fecal coliforms) and physicochemical ( $\mathrm{pH}$, turbidity, color and fluorides) analysis of the water from the springs show that the vegetation, even in the regeneration process is performing its role efficiently, since the laboratory results, taking as standard ones required by law (Decree no 518/2004 Ministry of Health and Resolution no 357/ 2005 CONAMA) did not detect contamination.

Key words: Montane Mixed Ombrophylous Forest; water spring; biological and physical-chemical test; floristic and phytosociologic composition. 


\section{Introdução}

A Floresta com Araucária que originalmente no Paraná se apresentava com uma cobertura de $73.780 \mathrm{~km}^{2}$, ocupando $37 \%$ da área total do Estado (MAACK, 2002), conta apenas com $0,8 \%$ de seus remanescentes naturais em estágio avançado de sucessão (FUPEF, 2001). Exploração madeireira, expansão da agricultura e instalação de empreendimentos agropecuários, associados à ausência de práticas adequadas para o uso do solo são, segundo a maioria dos autores, as principais causas apontadas para essa redução. Diante desse cenário, nem as florestas conhecidas como ciliares, ripárias ou de beiradeira (MARTINS, 1989), que se localizam ao longo dos rios e no entorno de nascentes, escaparam de tal sorte.

Vários autores, entre os quais Lima (1989), Barbosa (1999), Lima e Zakia (2000) e Oliveira (2001), têm ressaltado a importância das florestas ripárias numa bacia hidrográfica tanto do ponto de vista hidrológico como ecológico, já que manutenção da quantidade e qualidade da água, estabilidade do solo, preservação da biodiversidade e fornecimento de alimento para a fauna são algumas das funções atribuídas a esse tipo de vegetação. Ainda segundo Barbosa (1999), os solos sem a cobertura florestal reduzem drasticamente sua capacidade de retenção de água da chuva, a qual escoa sobre a superfície, formando enxurradas não permitindo o abastecimento do lençol freático. Além disso, as enxurradas provocam a erosão dos solos, podendo ocasionar o assoreamento do curso d'água, em especial das nascentes.

Definidas como aberturas naturais na superfície do terreno de onde escoam águas subterrâneas (CASTRO, 2001), as nascentes podem ser classificadas segundo o regime de chuvas, o tipo de reservatório e o estado de conservação (CASTRO; GOMES, 2001; PINTO et al., 2005). Quanto ao regime de chuvas elas se classificam em perenes (fluxo de água constante); temporárias (fluxo de água apenas na estação chuvosa) e efêmeras (os fluxos aparecem depois de uma chuva). Quanto ao tipo de reservatório, elas podem ser de encosta ou pontual (o fluxo d'água se dá em apenas um ponto do terreno) ou difusas (com vários olhos d'água). Já quanto ao estado de conservação, elas se classificam em preservadas (com pelo menos $50 \mathrm{~m}$ de vegetação natural ao seu redor e sem sinais de perturbação ou degradação), perturbadas (quando não apresentam os 50 $m$ de vegetação natural em seu redor, mas se encontram em bom estado de conservação) e degradadas (apresentando alto grau de perturbação, solo compactado com erosão ou voçoroca e vegetação escassa).

Apesar dos inúmeros serviços ambientais prestados pelas florestas ciliares, grande parte da vegetação ao redor das nascentes se encontram em desacordo com o que é estabelecido na alínea c do artigo $2^{\circ}$ do Código Florestal (Lei no 4.771/65), que determina que:

as florestas e demais formas de vegetação natural localizadas nas nascentes, ainda que intermitentes e nos chamados olhos de água, qualquer que seja a situação topográfica, devem ser preservadas num raio mínimo de 50 metros de tal forma que proteja a bacia hidrográfica constituinte.

Somando-se a isso, a escassez de estudos em remanescentes de Floresta Ombrófila Mista (FOM) localizados na região centro sul do estado (ISERNHAGEN, 
2001) deixam essa situação ainda mais crítica.

Assim, o presente estudo foi desenvolvido com o objetivo de contribuir para maior conhecimento da composição florística e estrutura fitossociológica de um trecho de FOM, com nascentes na zona rural de Guarapuava, além de analisar o papel protetivo da vegetação na qualidade da água tomando-se como padrão aqueles preconizados na legislação (Portaria no 518/2004 do Ministério da Saúde e Resolução no 357/2005 do CONAMA), já que de acordo com Pereira
(1973 apud LIMA, 1989) a conservação da qualidade da água não pode ser conseguida independentemente da conservação do solo.

\section{Material e Métodos}

Este estudo foi desenvolvido na zona rural do município de Guarapuava, estado do Paraná, na propriedade do Sr. Alfredo Maniz, a um patamar altimétrico de $1083 \mathrm{~m}$ entre as coordenadas geográficas $25^{\circ} 19^{\prime} 30^{\prime \prime} \mathrm{S}$ e $51^{\circ} 23^{\prime} 55^{\prime \prime} \mathrm{W}$ (Figura 1). Acessa-se o local pela rodovia BR-277.

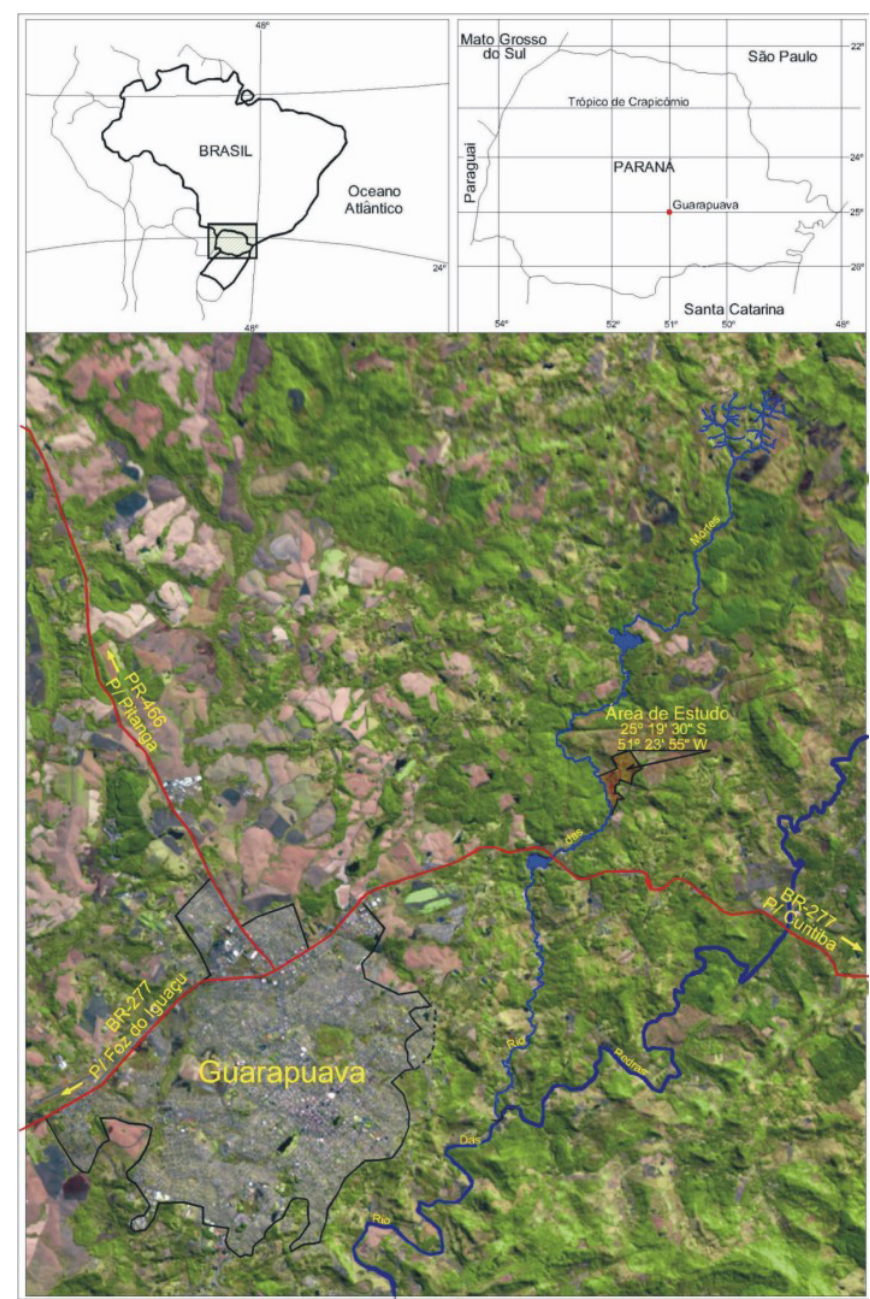

Figura I. Localização da área de estudo 
Dentro da propriedade, foi estudado um fragmento natural de vegetação, pouco antropizado, que protege duas nascentes do rio das Mortes, distanciadas 1,5 $\mathrm{m}$ uma da outra. Tal fragmento é classificado segundo o IBGE (1992) como Floresta Ombrófila Mista Montana (acima de $1000 \mathrm{~m}$ de altitude s.n.m.) inserida na grande região da estepe gramínea lenhosa do Sul do Brasil, localmente denominada de Campos de Guarapuava.

Com $21 \mathrm{~km}$ de extensão, o rio das Mortes ganha destaque por se constituir no principal contribuinte da bacia do rio das Pedras, de fundamental importância para a população de Guarapuava uma vez que se constitui em fonte de abastecimento hídrico para o Município. O rio das Pedras é contribuinte da bacia do rio Jordão, que, por sua vez, integra a bacia do rio Iguaçu.

O clima na região, segundo a classificação de Köppen, é do tipo Cfb, subtropical úmido mesotérmico, de verões frescos, inverno com geadas frequentes, sem estação seca (IAPAR, 2000). A pluviosidade mostra-se bem distribuída ao longo do ano, com precipitação média anual em torno de $1961 \mathrm{~mm}$ e com temperatura média anual oscilando em torno de 16 a $17,5^{\circ} \mathrm{C}$ (THOMAZ; VESTENA, 2003).

O relevo se apresenta fortemente ondulado na porção superior e mediana e médio ondulado na porção inferior que margeia as nascentes.

De acordo com os dados daEMBRAPA (1999), a região de Guarapuava é dominada pela ocorrência de Latossolos Brunos (distróficos ou álicos) com transições para Cambissolos, Terras Brunas Estruturadas e Litólicos, atualmente integrantes, respectivamente das classes Nitossolo e Neossolo (litólicos e regoliticos). Durante o estudo, pode-se observar que o solo da área se apresenta pouco desenvolvido e raso se enquadrando no tipo Neossolo Litólico (EMBRAPA, 1999).

A área de estudo está inserida na bacia sedimentar do Paraná, no conjunto litológico mesozóico, constituído por rochas sedimentares de origem continental, de idade triássica, e por rochas ígneas extrusivas de composição predominantemente básica de idade jurássica-cretácea, com 140-120 milhões de anos (MINEROPAR, 2001), na unidade morfoestrutural denominada Zona de Capeamento Basalto-Arenítico ou Terceiro Planalto, na subunidade Planalto dos Campos de Guarapuava (MAACK, 2002).

Para o levantamento florístico e análise da estrutura fitossociológica da área com nascentes, utilizou-se o método de parcelas múltiplas (MUELLERDOMBOIS; ELLENBERG, 1974). As 14 parcelas contínuas, de $10 \times 20$ metros $\left(2800 \mathrm{~m}^{2}\right)$ foram instaladas no entorno das nascentes. Dentro de cada parcela foram mensurados todos os indivíduos com perímetro à altura do peito (PAP) igual ou superior a 15 centímetros. Esses indivíduos, após serem identificados, receberam uma numeração sequencial e tiveram anotado em ficha de campo seu valor de DAP e altura. Os procedimentos de coleta e herborização utilizados seguiram as técnicas citadas em IBGE (1992). A identificação taxonômica foi realizada em campo, com base nos aspectos dendrológicos das espécies e em laboratório, por meio de literatura especializada e envio de material para especialista. Os nomes das espécies foram verificados no IPNI (2007), sendo utilizadas as abreviaturas dos autores sugeridas por Brummit e Powell (1992). Todo material 
coletado foi incorporado ao Herbário do Colégio Florestal de Irati.

Para a compilação dos dados e representação gráfica dos resultados, empregou-se o software ${ }^{\circledR}$ Excel for Windows, enquanto que para o processamento dos dados para o cálculo de descritores (densidade, dominância, frequência e valor de importância) usou-se o programa STRUCT.bas ${ }^{5}$. O índice de diversidade de Shannon-Weaver ( $\left.H^{\prime}\right)$ foi obtido segundo Magurran (1988), expresso pela fórmula $H^{\prime}=-\sum_{i=1}^{S}\left[p_{i} h\left(p_{i}\right)\right] \operatorname{com} p_{i}=\frac{n_{i}}{N}$, onde pi $=$ proporção de indivíduos da i-ésima espécie; ni = é o número de árvores da espécies i e $\mathrm{N}$ = é o número total de árvores amostradas.

A suficiência amostral foi determinada pela curva espécies-área (BRAUNBLANQUET, 1950; GALVÃO, 1994).

Para a avaliação da qualidade da água das nascentes, foi realizado uma coleta em

5 SOLTER, F. STRUCT.bas. Curitiba, Universidade Federal do Paraná, UFPR, [s.d.] (comunicação) frascos especiais e o material coletado foi encaminhado ao laboratório da SANEPAR em Guarapuava, para análises biológica e físico-química, tomando-se como padrão aqueles previstos na Portaria no 518/2004 do Ministério da Saúde e na Resolução no 357/2005 do Conselho Nacional do Meio Ambiente CONAMA. $\mathrm{Na}$ análise biológica foi analisado a presença de coliformes totais e termotolerantes e na físico-química foram analisadas as variáveis $\mathrm{pH}$, cor, turbidez e fluoretos.

\section{Resultados e Discussão}

Para os $2800 \mathrm{~m}^{2}$ amostrados, foram registrados 484 indivíduos, com uma densidade absoluta de 1728,57 indivíduos/ha, distribuídos ao longo das 14 parcelas amostradas.

Por meio da expressão gráfica externada pela curva espécie/área, podese verificar que o esforço amostral foi suficiente quando se considerou a totalidade de parcelas alocadas (Figura 2), a ponto de provocar uma visível estabilização na curva

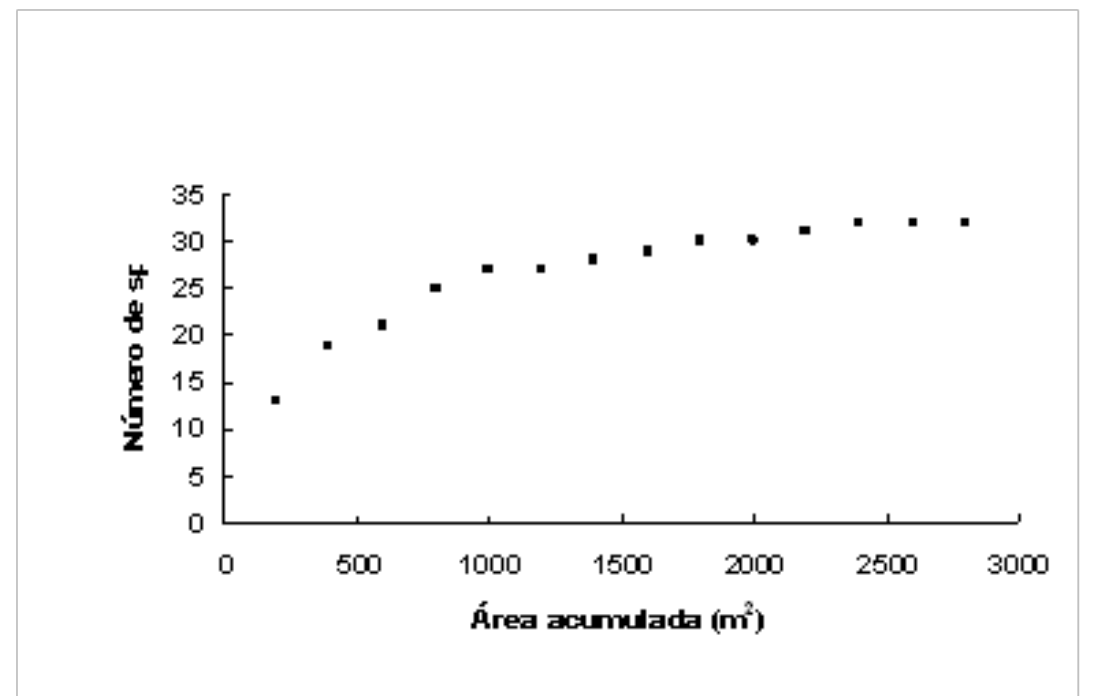

Figura 2. Curva espécie/área do fragmento de Floresta Ombrófila Mista Montana com nascentes do rio das Mortes, no município de Guarapuava (PR) 
próximo dos $2400 \mathrm{~m}^{2}$, ou seja a partir da $12^{\underline{a}}$ parcela.

Os indivíduos arbóreos identificados por ocasião do levantamento fitossociológico estão distribuídos em 22 famílias com 32 espécies. Resultados semelhantes foram encontrados por Cordeiro (2005), em área de FOM no Parque Municipal das Araucárias, também em Guarapuava.

No tabela 1 , estão relacionadas as espécies encontradas em ordem alfabética de famílias e gêneros e seus nomes vulgares.

Tabela I. Composição florística de um fragmento protetivo de Floresta Ombrófila Mista Montana com nascentes do rio das Mortes em Guarapuava

\begin{tabular}{|c|c|}
\hline $\begin{array}{l}\text { Família } \\
\text { Espécie/Autor }\end{array}$ & Nome vulgar \\
\hline \multicolumn{2}{|l|}{ ANACARDIACEAE } \\
\hline Schinus polygamus (Cav.) Cabrera & Mosqueteiro \\
\hline Scbinus terebintbifolius Raddi & Aroeira \\
\hline \multicolumn{2}{|l|}{ ANNONACEAE } \\
\hline Annona rugulosa (Schltdl.) H. Rainer & Ariticum \\
\hline \multicolumn{2}{|l|}{ AQUIFOLIACEAE } \\
\hline Ilex brevicuspis Reissek & Voadeira \\
\hline Ilex paraguariensis A.St.-Hil. & Erva-mate \\
\hline \multicolumn{2}{|l|}{ CAPRIFOLIACEAE } \\
\hline Sambucus australis Cham.\& Schltdl. & Sabugueiro \\
\hline \multicolumn{2}{|l|}{ CLETHRACEAE } \\
\hline Clethra scabra Pers. & Carne de vaca \\
\hline \multicolumn{2}{|l|}{ ELAEOCARPACEAE } \\
\hline Sloanea monosperma Vell. & Laranja do mato \\
\hline \multicolumn{2}{|l|}{ ERYTHROXYLLACEAE } \\
\hline Erytbroxyllum deciduum A.St.-Hil. & Marmeleiro bravo \\
\hline \multicolumn{2}{|l|}{ EUPHORBIACEAE } \\
\hline Sapium glandulosum (L.) Morong & Leiteiro \\
\hline \multicolumn{2}{|l|}{ FABACEAE } \\
\hline Erythrina falcata Benth. & Corticeira \\
\hline Lonchocarpus mueblbergianus Hassl. & Timbó \\
\hline Mimosa scabrella Benth. & Bracatinga \\
\hline \multicolumn{2}{|l|}{ LAURACEAE } \\
\hline Nectandra saligna Nees & Canela \\
\hline Ocotea porosa (Ness) Barroso & Imbuia \\
\hline Ocotea puberula (Rich.) Nees & Canela guaicá \\
\hline \multicolumn{2}{|l|}{ LAXMANNIACEAE } \\
\hline Cordyline spectabilis Kunth \& Bouché & Uvarana \\
\hline
\end{tabular}


(continuação...)

\begin{tabular}{ll}
\hline Família & Nome vulgar \\
Espécie/Autor & \\
\hline MELASTOMATACEAE & Pixirica \\
Miconia cinerascens Miq. & \\
MELIACEAE & Cedro \\
Cedrella fissilis Vell. & \\
MYRSINACEAE & Capororoquinha \\
Myrsine coriaceae (Sw.) R. Br. Ex Roem. & \\
MYRTACEAE & Guabiroba \\
Campomanesia xanthocarpa O. Berg & \\
RHAMNACEAE & Fruto-de-pombo \\
Rhamnus sphaerosperma Sw. & \\
ROSACEAE & Pessegueiro bravo \\
Prunus brasiliensis Schott ex Spreng. & \\
RUTACEAE & Mamica de cadela \\
Zanthoxylum rhoifolium Lam. & \\
SAPINDACEAE & Vacum \\
Allophylus edulis (A.St.-Hil.et al.) Hieron. ex Niederl. & Cuvatã \\
Cupania vernalis Cambess. & Miguel pintado \\
Matayba elaeagnoides Radlk. & \\
SOLANACEAE & Fumo bravo \\
Solanum fastigiatum Willd. & Cuvitinga \\
Solanum granulosoleprosum Dunal & \\
Solanum pseudoquina A.St.-Hil. & Maria mole \\
STYRACACEAE & \\
Styrax leprosus Hook. \& Arn. & \\
SYMPLOCACEAE & \\
Symplocos uniflora (Pohl) Benth. & \\
\hline & \\
&
\end{tabular}

A composição florística do remanescente de FOM estudado apresenta boa diversidade de espécies. Embora no local tenha sido observado exemplares de Araucaria angustifolia (Bertol.) Kuntze (araucária), característico deste tipo de formação, eles não chegaram a ser amostrados por não terem atingido a medida mínima de PAP definida como critério de inclusão. Esse fato vem de encontro com as informações obtidas com o filho do proprietário, de que há aproximadamente 40 anos atrás, neste local foram seletivamente abatidos exemplares arbóreos, de araucária, cedro (Cedrela fissilis) e imbuia (Ocotea porosa). Por outro lado, não foi encontrado na área nenhum representante da espécie Podocarpus lambertii Klotzsh ex Endl. citada como típica neste tipo de formação florestal (VELOSO, 1962; IBGE, 1992; KLEIN, 1984).

Com base no tabela 1, observa-se que, a riqueza intraespecífica, não é alta. Fabaceae, 
Lauraceae, Sapindaceae e Solanaceae, foram as famílias que apresentaram maior riqueza, com 3 espécies, seguidas por Anacardiaceae e Aquifoliaceae com duas. As demais, que perfazem $74 \%$ do total das espécies amostradas, apresentaram somente uma única espécie. Esta condição de famílias monoespecíficas também foi observada nos estudos de Durigan (1999) no município de São João do Triunfo (50\%); Negrelle e Leuchtenberger (2001) no de Ponta Grossa $(55,17 \%)$ e Cordeiro (2005) no de Guarapuava (60\%).

Entretanto, apesar da pouca variedade intraespecífica encontrada, o fragmento estudado contém representantes típicos das familias que ocorrem com maior frequência na FOM, como é caso das Lauraceae, Myrtaceae, Fabaceae e Sapindaceae (IBGE, 1992; LEITE, 1994; RODERJAN et al., 2002).

As espécies amostradas nessa área com seus respectivos parâmetros fitossociológicos em ordem decrescente de valor de importância (VI\%) são apresentadas na tabela 2. Nela se observa que as seis espécies mais representativas são Matayba elaeagnoides (56,07\%); Ocotea puberula (51,12\%); Mimosa scabrella (30,66\%); Myrsine coriacea (24,57); Erythrina falcata $(17,02 \%)$ e Solanum pseudoquina $(15,26 \%)$. Elas respondem, aproximadamente, por $70,25 \%$ do total da densidade e por $85,55 \%$ do total da dominância. A pouca representatividade na amostra principalmente em termos de dominância foi o fator mais representativo para as espécies com VI\% abaixo de 15 . O baixo valor encontrado para esse parâmetro $\left(29,82 \mathrm{~m}^{2} / \mathrm{ha}\right)$ pode ser explicado pelo grande número de indivíduos com diâmetros finos, o que segundo Longhi (1980) caracteriza um fragmento em fase secundária, já que florestas primárias registram valores de dominância superiores a $35 \mathrm{~m}^{2} / \mathrm{ha}$.
A alta frequência de Ocotea puberula, Myrsine coriacea e Allophylus edulis, presentes em aproximadamente $79 \%$ das parcelas, só vem reforçar a grande plasticidade dessas espécies. Além dessas, outras que também apresentaram certa regularidade na distribuição de seus indivíduos foram: Matayba elaeagnoides, Mimosa scabrella, Solanum pseudoquina, Nectandra saligna e Schinus terebinthifolius ocorrendo em mais de $60 \%$ das parcelas.

O maior valor de importância do fragmento, ocupado pela espécie Matayba elaeagnoides, é consequência, principalmente, de seu maior valor de densidade (642,86 ind/ ha). Esse valor, quase quatro vezes maior do que o observado para aquela que ocupa o segundo maior VI\%, só vem reforçar a hipótese de Durigan (1999) de que Matayba elaeagnoides, conhecida popularmente pelo nome de miguel pintado, é uma espécie habitual de solos bem drenados, característico de áreas de Floresta Ombrófila Mista Montana.

Respondendo pelo segundo maior valor aparece Ocotea puberula, popularmente designada de canela guaicá. Trata-se da espécie de maior porte na área de estudo, uma vez que responde pelo maior valor de dominância $\left(10,09 \mathrm{~m}^{2} / \mathrm{ha}\right)$. A ocorrência desta espécie com tais dimensões demonstra que o fragmento mantém características da composição florística original.

A terceira posição no "ranking" de VI\% é ocupada por uma espécie pioneira típica das formações secundárias da Floresta com Araucária, denominada Mimosa scabrella. Conhecida pelo nome vulgar de bracatinga, tal espécie responde pelo segundo maior valor de dominância $\left(5,78 \mathrm{~m}^{2} / \mathrm{ha}\right) \mathrm{da}$ área. Sua presença só vem reforçar o fato de que o fragmento sofreu alterações antrópicas no passado. 
Tabela 2. Estimativa dos parâmetros fitossociológicos das espécies arbóreas do fragmento protetivo da Floresta Ombrófila Mista Montana em área de nascentes do rio das Mortes em Guarapuava (PR)

\begin{tabular}{|c|c|c|c|c|c|c|c|c|}
\hline \multirow[b]{2}{*}{ Espécie } & \multirow[b]{2}{*}{$\mathbf{N}$} & \multicolumn{2}{|c|}{ Densidade } & \multicolumn{2}{|c|}{ Dominância } & \multicolumn{2}{|c|}{ Frequência (\%) } & \multirow[b]{2}{*}{$\begin{array}{l}\text { VI } \\
(\%)\end{array}$} \\
\hline & & $\begin{array}{c}\text { DA } \\
\text { (N/ha) }\end{array}$ & $\begin{array}{l}\text { DR } \\
\text { (\%) }\end{array}$ & $\begin{array}{l}\text { DoA } \\
\text { (m2/ } \\
\text { ha) }\end{array}$ & $\begin{array}{c}\text { DoR } \\
\text { (\%) }\end{array}$ & FA & FR & \\
\hline Matayba elaeagnoides & 180 & 642,86 & 37,2 & 3,63 & 12,16 & 71,43 & 6,71 & 56,07 \\
\hline Ocotea puberula & 48 & 171,43 & 9,91 & 10,09 & 33,83 & 78,57 & 7,38 & 51,12 \\
\hline Mimosa scabrella & 22 & 78,57 & 4,55 & 5,78 & 19,4 & 71,43 & 6,71 & 30,66 \\
\hline Myrsine coriacea & 45 & 160,71 & 9,3 & 2,35 & 7,89 & 78,57 & 7,38 & 24,57 \\
\hline Erythrina falcata & 12 & 42,86 & 2,48 & 3,14 & 10,51 & 42,86 & 4,04 & 17,02 \\
\hline Solanum pseudoquina & 33 & 117,86 & 6,82 & 0,52 & 1,73 & 71,43 & 6,71 & 15,26 \\
\hline Nectandra saligna & 14 & 50 & 2,9 & 1,46 & 4,89 & 71,43 & 6,71 & 14,50 \\
\hline Allophylus edulis & 24 & 85,71 & 4,96 & 0,24 & 0,8 & 78,57 & 7,38 & 13,14 \\
\hline Annona rugulosa & 23 & 82,14 & 4,75 & 0,39 & 1,29 & 64,29 & 6,04 & 12,08 \\
\hline Schinus terebinthifolius & 18 & 64,29 & 3,72 & 0,21 & 0,69 & 64,29 & 6,04 & 10,45 \\
\hline Ocotea porosa & 11 & 39,29 & 2,27 & 0,26 & 0,89 & 42,86 & 4,03 & 7,19 \\
\hline Zanthoxylium rhoifolium & 6 & 21,43 & 1,24 & 0,16 & 0,52 & 35,69 & 3,35 & 5,11 \\
\hline Ilex brevicuspis & 5 & 17,86 & 1,03 & 0,22 & 0,74 & 28,56 & 2,68 & 4,45 \\
\hline Cupania vernalis & 4 & 14,29 & 0,83 & 0,08 & 0,25 & 28,56 & 2,68 & 3,76 \\
\hline Solanum granulosoleprosum & 3 & 10,71 & 0,62 & 0,3 & 1,01 & 21,43 & 2,02 & 3,65 \\
\hline Sambucus australis & 4 & 14,29 & 0,83 & 0,12 & 0,41 & 21,43 & 2,02 & 3,26 \\
\hline Clethra scabra & 3 & 10,71 & 0,62 & 0,06 & 0,2 & 21,43 & 2,02 & 2,84 \\
\hline Schinus polygamus & 3 & 10,71 & 0,62 & 0,04 & 0,12 & 21,43 & 2,02 & 2,76 \\
\hline Cedrella fissilis & 3 & 10,71 & 0,62 & 0,22 & 0,72 & 14,29 & 1,34 & 2,68 \\
\hline Rhamnus sphaerosperma & 4 & 14,29 & 0,83 & 0,09 & 0,31 & 14,29 & 1,34 & 2,48 \\
\hline Solanum fastigiatum & 3 & 10,71 & 0,62 & 0,06 & 0,2 & 14,29 & 1,34 & 2,16 \\
\hline Sapium glandulosum & 2 & 7,14 & 0,41 & 0,09 & 0,29 & 14,29 & 1,34 & 2,04 \\
\hline Sloanea monosperma & 2 & 7,14 & 0,41 & 0,03 & 0,11 & 14,29 & 1,34 & 1,87 \\
\hline Prunus brasiliensis & 2 & 7,14 & 0,41 & 0,02 & 0,07 & 14,29 & 1,34 & 1,82 \\
\hline Lonchocarpus muehlbergianus & 2 & 7,14 & 0,41 & 0,22 & 0,06 & 14,29 & 1,34 & 1,81 \\
\hline Ilex paraguariensis & 2 & 7,14 & 0,41 & 0,14 & 0,46 & 7,14 & 0,67 & 1,54 \\
\hline Cordyline spectabilis & 1 & 3,57 & 0,21 & 0,04 & 0,12 & 7,14 & 0,67 & 1,00 \\
\hline Erytbroxyllum deciduum & 1 & 3,57 & 0,21 & 0,04 & 0,12 & 7,14 & 0,67 & 1,00 \\
\hline Miconia cinerascens & 1 & 3,57 & 0,21 & 0,02 & 0,07 & 7,14 & 0,67 & 0,95 \\
\hline Stirax leprosus & 1 & 3,57 & 0,21 & 0,02 & 0,07 & 7,14 & 0,67 & 0,95 \\
\hline Symplocos uniflora & 1 & 3,57 & 0,21 & 0,01 & 0,03 & 7,14 & 0,67 & 0,91 \\
\hline Campomanesia xanthocarpa & 1 & 3,57 & 0,21 & 0,01 & 0,02 & 7,14 & 0,67 & 0,90 \\
\hline TOTAL & 484 & 1728,57 & 100,00 & 29,82 & 100,00 & 1064,27 & 100,00 & 300,00 \\
\hline
\end{tabular}


A quarta posição é ocupada por Myrsine coriacea (capororoquinha) em razão de seus valores de densidade $(160,71$ ind/ha) e frequência $(78,77 \%)$.

Espécie comum em floresta de altitude, Erythrina falcata, conhecida popularmente pelo nome de corticeira, responde pelo quinto valor de VI. Presente em aproximadamente $43 \%$ das parcelas, esta espécie se sobressai em dominância $\left(3,14 \mathrm{~m}^{2} / \mathrm{ha}\right)$ entre as demais com valores menores de VI\%.

A sexta posição é ocupada por Solanum pseudoquina (joazeiro), em razão principalmente de seu valor de densidade (117,86 ind/ha). Embora seja encontrada em $72 \%$ das parcelas, seus exemplares são representados por árvores de pequenas dimensões, o que pode ser traduzido pela baixa taxa de dominância apresentada $\left(0,52 \mathrm{~m}^{2} / \mathrm{ha}\right)$.

A partir da sétima posição, os parâmetros que mais influenciaram para a classificação das espécies quanto ao VI\% foram densidade e frequência. No caso daquelas influenciadas pela densidade, o que se observa é que elas se encontram em processo inicial de regeneração, constatado pelos baixos valores de dominância. Por outro lado, no caso daquelas influenciadas pela frequência o que se nota é que elas estão concentradas em poucas parcelas, indicando um certo grau de gregarismo.

Ainda com relação à tabela 2 , verificou-se que $59,4 \%$ do total de espécies amostradas (19) possuem densidade relativa inferior a $1 \%$, indicando que essas espécies possuem uma representatividade baixa na área. A comparação entre estes valores vem ao encontro da exposição de
Martins (1989), para quem a riqueza de espécies arbóreas e altos índices de espécies raras condicionam às florestas brasileiras uma estrutura fitossociológica muito particular, caracterizada por apresentar espécies com valores de importância muito semelhantes e pouco representativos na composição da estrutura.

O valor estimado do índice de diversidade de Shannon foi de 2,406 nats/ ind. Este valor ficou abaixo dos obtidos em estudos fitossociológicos na FOM, no primeiro e segundo planalto do Estado: Negrelle e Leuchtenberger (2001), com 3,54; Durigan (1999), com 3,52; Rondon Neto et al. (2002), com 3,44, porém, bastante próximo daqueles observados em estudos no terceiro planalto, na região de Guarapuava: Silva (2003), com 3,36; FUPEF (2003), com 2,80 e Cordeiro (2005), com 2,79. Essa baixa diversidade florística é comum, segundo Roderjan et al. (2002), nos remanescentes de FOM que se encontram em áreas de maior altitude onde os rigores climáticos exercem pressão seletiva sobre a diversidade vegetal.

A distribuição diamétrica da floresta em geral (Figura 3) segue o padrão observado nas florestas naturais heterogêneas e multietâneas (MACHADO et al., 1987), ou seja, apresenta uma distribuição exponencial na forma de "J" invertido. Isso aponta para um bom desenvolvimento da floresta, com muitos representantes nas primeiras classes, havendo uma diminuição gradativa conforme o aumento de diâmetro. Esse tipo de distribuição, segundo Longhi (1980), garante que o processo dinâmico da floresta se perpetue. 


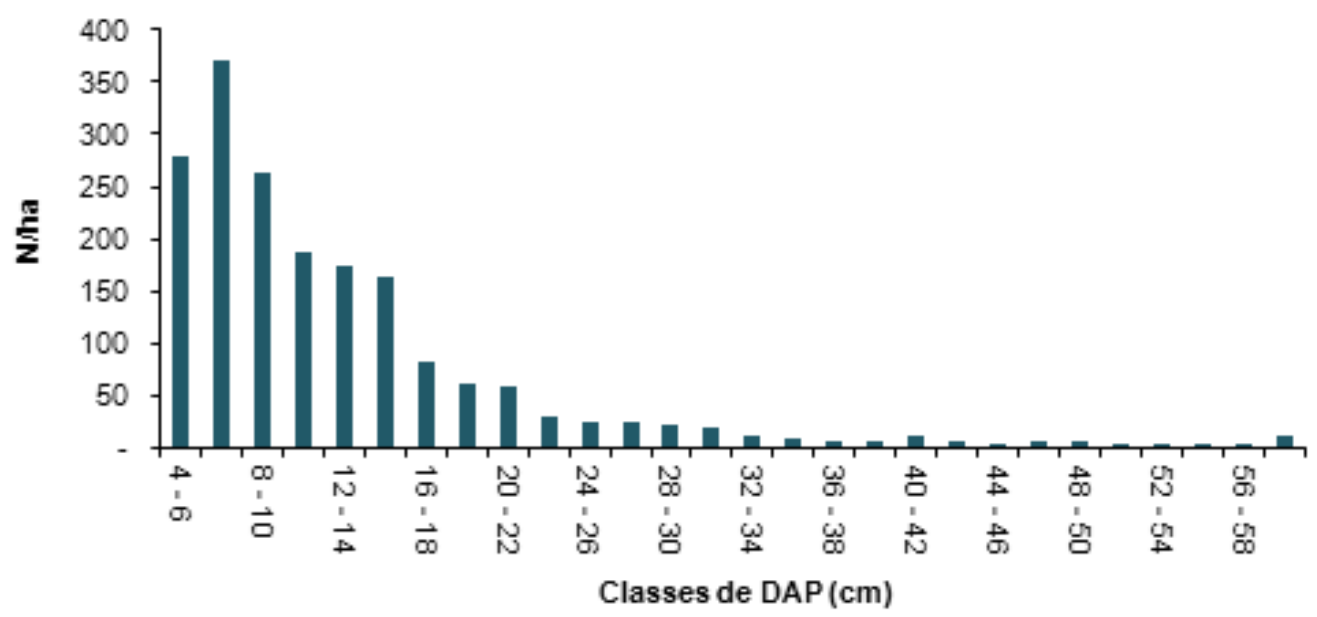

Figura 3. Distribuição diamétrica, por classes de DAP, dos indivíduos amostrados no fragmento protetivo de Floresta Ombrófila Mista Montana, com nascentes do rio das Mortes em Guarapuava (PR)

Os resultados do exame bacteriológico (segundo a Portaria do Ministério da Saúde no 518/2004 e a Resolução do CONAMA no 357/2005) de amostras de água das nascentes, classificadas segundo Castro e Gomes (2001) e Pinto et al. (2005) em perenes (quanto ao regime de água); pontuais ou de encostas (quanto ao tipo de reservatório) e perturbadas (quanto ao estado de conservação), encontramse descritos na tabela 3 .

Por meio da análise dessa tabela, podese observar que a água colhida no fragmento com nascentes está isenta de coliformes fecais ou seja não contaminada com fezes humanas.
Por sua vez, quanto aos coliformes totais, embora apresentando uma fração mínima de contaminante ainda é considerada como ausente de poluente, segundo a portaria. Cabe lembrar que essa fração mínima de contaminantes (fezes de animais) pode ser explicada pelo fato de que, té o começo desse estudo os animais ficavam soltos na área.

$\mathrm{Na}$ tabela 4, encontram-se descritos os resultados do exame físico-químico realizado com a amostra de água das nascentes tomandose como padrão aqueles previstos na Portaria do Ministério da Saúde no 518/2004 e na Resolução do CONAMA no 357/2005.

Tabela 3. Resultado da análise bacteriológica da água retirada das nascentes do rio das Mortes encontradas em um fragmento protetivo de Floresta Ombrófila Mista Montana em Guarapuava (PR)

\begin{tabular}{lcc}
\hline \multicolumn{1}{c}{ Parâmetro } & Resultado $^{(1)}$ & ${\text { VMP }- \text { Portaria }^{(2)}}^{1}$ \\
\hline Coliformes Totais & 0,001 & AUSENTE \\
Coliformes Termotolerantes & 0 & AUSENTE \\
\hline
\end{tabular}

Nota: (I)Os resultados bacteriológicos obtidos são em $100 \mathrm{ml}$ e devem ser multiplicados por 1000.

(2) VMP - Portaria: Refere-se a portaria 5 I8/04 do Ministério da saúde que dispõe o volume máximo permitido (VMP) para água produzida e distribuída. 
Tabela 4. Resultado da análise físico - química da água retirada das nascentes do rio das Mortes localizada em um fragmento protetivo de Floresta Ombrófila Mista Montana em Guarapuava (PR)

\begin{tabular}{lcc}
\hline \multicolumn{1}{c}{ Parâmetro } & Resultado & VMP - Portaria \\
\hline Cor aparente (QH - Un. Cor) & 2,5 & 15 \\
Fluoretos (mg / 1 F) & 0 & 0,6 a 1,1 \\
Turbidez (NTU) & 0,63 & 5 \\
$\mathrm{pH}$ (Un. pH) & 6,3 & 5,4 a 10 \\
\hline
\end{tabular}

Assim como na análise biológica, os resultados obtidos na análise físico química estão bem abaixo dos valores limites adotados como requisito normativo de qualidade da água, indicando que a água que brota dessas nascentes é de boa qualidade.

Com base no exposto pode-se inferir que, na área coberta por floresta natural onde estão localizadas às nascentes, a vegetação esta desempenhando de maneira eficiente o seu papel de proteção contra erosão do solo, a sedimentação e a lixiviação excessiva de nutrientes, além de filtrar resíduos de produtos químicos, de fundamental importância para a preservação da qualidade da água.

\section{Conclusões}

A área em estudo é considerada como um importante remanescente de Floresta Ombrófila Mista, se constituindo em Área de Preservação Permanente (APP) em razão das nascentes encontradas em seu interior.

A estrutura e a fisionomia aparente da vegetação ali encontrada foram consideradas como indicativo de que interferências antrópicas ocorreram no passado.
Os mais altos valores relativos densidade e de dominância, respectivamente, foram os quesitos que mais contribuíram para que as espécies Matayba elaeagnoides e Ocotea puberula fossem classificadas como as principais do fragmento.

Como os resultados dos exames bacteriológico e físico-químico de amostras de água das nascentes, realizados pela SANEPAR, estão bem abaixo daqueles previstos pela Portaria no 518/2004 do Ministério da Saúde e pela Resolução no 357/2005 do CONAMA, pode-se concluir que o fragmento mesmo em processo de regeneração, com uma estrutura florística incompleta, está desempenhando seu papel protetivo no quesito qualidade da água.

\section{Agradecimentos}

Ao Professor Ronald Medeiros, Sr. Augusto Andreola, ao acadêmico Fabio Gaffke, à SANEPAR (unidade Guarapuava) e ao Instituto Ambiental do Paraná (unidade Guarapuava) pela colaboração no trabalho de campo.

Ao Fábio Solter, engenheiro florestal que disponibilizou o Programa STRUCT.bas para o cálculo dos índices fitossociológicos.

\section{Referências}

BARBOSA, L. M. Implantação de mata ciliar. In.: SIMPÓSIO SOBRE MATA CILIAR: CIÊNCIA E TECNOLOGIA, 1989, Belo Horizonte. Anais... Belo Horizonte: UFL, 1999. p.111-135. 
BRASIL. Lei no 4.771, de 15 de setembro de 1965. Institui o novo Código Florestal. Diário Oficial [da] União, Brasília, DF, 16 set. 1965.

BRASIL. Portaria no 518, de 25 de março de 2004. Estabelece os procedimentos e responsabilidades relativos ao controle e vigilância da qualidade da água para consumo humano e seu padrão de potabilidade, e dá outras providências. Diário Oficial [da] União, Brasília, DF, 26 mar. 2004.

BRASIL. Resolução CONAMA 357, de 17 de março de 2005. Dispõe sobre a classificação dos corpos de água e diretrizes ambientais para o seu enquadramento, bem como estabelece as condições e padrões de lançamento de efluentes, e dá outras providências. Diário Oficial [da] União, Brasília, DF, 18 mar. 2005.

BRAUN-BLANQUET, J. Sociología vegetal: estudio de las comunidades vegetales. Buenos Aires: Acme Agency, 1950.

BRUMMIT,R.K.;POWEL,C.E.Authors of Plant Names. Kew: Royal Botanic Gardens, 1992.

CASTRO, P. S. Recuperação e conservação de nascentes. Série saneamento e meio ambiente, n.26, p.1-84, 2001.

CASTRO, P. S.; GOMES, M. A. Técnicas de conservação de nascentes. Ação Ambiental, Viçosa, v.4, n.20, p.24 -26, out./nov. 2001.

CORDEIRO, J. Levantamento florístico e caracterização fitossociológica de um remanescente de floresta ombrófila mista em Guarapuava - PR. 2005. 131 f. Dissertação (Mestrado em Botânica) - Universidade Federal do Paraná, Curitiba, 2005.

DURIGAN, M. E. Florística, dinâmica e análise protéica de uma floresta ombrófila mista em São João do Triunfo - PR. 1999. 125f. Dissertação (Mestrado em Engenharia Florestal) - Universidade Federal do Paraná, Curitiba, 1999.

EMBRAPA. Centro Nacional de Pesquisa de Solos. Sistema Brasileiro de Classificação de Solos. Brasília: Embrapa Produção de Informações. Rio de Janeiro: Embrapa Solos, 1999. 412p.

FUPEF. Fundação de Pesquisas Florestais do Paraná. Conservação do bioma floresta com Araucária. Relatório final. Diagnóstico dos remanescentes florestais florestais/PROBIO Araucária, Curitiba: FUPEF, 2001, 236p.

FUPEF. Fundação de Pesquisas Florestais do Paraná. Diagnóstico da cobertura vegetal da área proposta para a construção da PCH São Jerônimo e do contexto vegetacional do seu entorno. Curitiba: FUPEF, 2003.

GALVÃO, F. Métodos de levantamento fitossociológico. In: A vegetação natural do Estado do Paraná. Curitiba: IPARDES, CTD, 1994. 
IAPAR. Instituto Agronômico do Paraná. Cartas climáticas do Paraná. Londrina: IAPAR, 2000. Versão 1.0.

IBGE. Instituto Brasileiro de Geografia e Estatística. Manual Técnico da Vegetação Brasileira, Manuais Técnicos em Geociências, Rio de Janeiro: IBGE, n.1, 1992. 91p.

IPNI. International Plant Name Index. Disponível em: <http://www.ipni.org >. Acesso em: 22 jun. 2007.

ISERNHAGEN, I. A fitossociologia florestal no paraná e os programas de recuperação de áreas degradadas: uma avaliação. 2001. 134 f. Dissertação (Mestrado em Botânica) - Setor de Ciências Biológicas, Universidade Federal do Paraná, Curitiba, 2001.

KLEIN, R. M. Aspectos dinâmicos da vegetação do sul do Brasil. Selowia, Itajaí, n.36, p.5-54, 1984.

LEITE, P. F. As diferentes unidades fitoecológicas da Região Sul do Brasil - Proposta de Classificação. 1994. 160 f. Tese (Doutorado em Engenharia Florestal) - Setor de Ciências Agrárias, Universidade Federal do Paraná, Curitiba, 1994.

LIMA, W. P. Função hidrológica da mata ciliar. In: SIMPÓSIO SOBRE MATA CILIAR, 1989, São Paulo. Anais... Campinas: Fundação Cargil, 1989. p.25-42.

LIMA, W. P.; ZAKIA, M. J. B. Hidrologia em matas ciliares. In: RODRIGUES, R. R.; LEITÃO-FILHO, H. (Org.) Matas ciliares: conservação e recuperação. São Paulo: USP/ FAPESP, 2000. p.33-44.

LONGHI, S. J. A estrutura de uma floresta natural de Araucária angustifolia (Bert.) O. Ktze, no sul do Brasil. 1980. 198 f. Dissertação (Mestrado em Engenharia Florestal) Universidade Federal do Paraná, Curitiba, 1980.

MAACK, R. Geografia física do estado Paraná. 3.ed. Curitiba: Imprensa Oficial, 2002.450p.

MACHADO, S. A.; BARTOSZEK, A. C. P. S.; OLIVEIRA, E. B. de. Estudo da estrutura diamétrica para Araucaria angustifolia em florestas naturais nos estados da região sul do Brasil. Floresta, Curitiba, v.1/2, n.26, p.59-70, 1987.

MAGURRAN, A. E. Diversidad ecologica y su medición. Barcelona: Vedra, 1988. 200p.

MARTINS, F. R. Fitossociologia de florestas do Brasil: um histórico bibliográfico. Pesquisa Série Botânica, v.40, p.105-161, 1989.

MINEROPAR - Minerais do Paraná S.A. Diagnóstico preliminar dos impactos ambientais da mineração no Paraná. Curitiba: 2001. 207p.

MUELLER-DOMBOIS, D.; ELLEMBER, H. Aims and methods of vegetation ecology. New York: John Wiley \& Sons, 1974. 547p. 
NEGRELLE, R.A.B.; LEUCHTENBERGER, R. Composição e estrutura do componente arbóreo de um remanescente de Floresta Ombrófila Mista. Floresta, Curitiba, v.1 e 2, n.31, p.42-51, 2001.

OLIVEIRA, E. A. Caracterização florística, fitossociológica e pedológica de um trecho de floresta ripária dos Campos Gerais do Paraná. 2001. 106 f. Dissertação (Mestrado) - Setor de Ciências Agrárias, Universidade Federal do Paraná, Curitiba, 2001.

PINTO, L. V. A.; DAVIDE, A. C.; BOTELHO, S. A.; OLIVEIRA-FILHO, A. T.; MACHADO, E. L. M. Distribuição das espécies arbóreo-arbustivas ao longo do gradiente de umidade do solo de nascentes pontuais da bacia hidrográfica do Ribeirão Santa Cruz, Lavras, MG. Cerne, Lavras, v.11, n.3, p.294-305, 2005.

RODERJAN, C. V.; GALVÃO, F.; KUNIYOSHI, Y. S.; HATSCHBACH, G. G. As unidades fitogeográficas do estado do Paraná. Ciência \& Ambiente, Santa Maria, RS, n.24, p.75-92, jan./jun. 2002.

RONDON NETO, R. M.; KOZERA, C.; ANDRADE, R. R.; CECY, A. T.; HUMMES, A. P.; FRITZSONS, E.; CALDEIRA, M. V. W.; MACIEL, M. N. M.; SOUZA, M. K. F. Caracterização florística e estrutural de um fragmento de floresta ombrófila mista, em Curitiba, PR - Brasil. Floresta, Curitiba, n.32, v.1, p.3-16, 2002.

SILVA, D. W. Florística e Fitossociologia de dois remanescentes de Floresta Ombrófila mista (floresta com araucária) e análise de duas populações de Araucaria angustifolia (Bertol.) O. Kuntze na região de Guarapuava, PR. 2003. 160f. Tese (Doutorado em Ecologia) - Centro de Ciências Biológicas e da Saúde, Universidade Federal de São Carlos, São Carlos, 2003.

THOMAZ,E. L.; VESTENA, L. R.Aspectos climáticos de Guarapuava-PR. Guarapuava: UNICENTRO, 2003.106p.

VELOSO,H.P. Os grandes clímaces do Brasil.I - Considerações sobre os tipos vegetativos da região sul. Memórias do Instituto Oswaldo Cruz, Rio de Janeiro, n.2, p.175-190, 1962. 